\title{
Atmospheric Corrosion Studies of Ductile Iron and Austenitic Stainless Steel in an Extreme Marine Environment
}

\author{
Olasupo Ogundare ${ }^{1 *}$, Babaniyi Babatope ${ }^{2}$, Adelana Razaq Adetunji ${ }^{3,4}$, \\ Samuel Olugbenga Oloruntoba Olusunle ${ }^{5}$ \\ ${ }^{1}$ Engineering Materials Development Institute, Akure, Nigeria \\ ${ }^{2}$ Department of Physics, Obafemi Awolowo University, Ile-Ife, Nigeria \\ ${ }^{3}$ Department of Materials Science and Engineering, Obafemi Awolowo University, Ile-Ife, Nigeria \\ ${ }^{4}$ Prototype Engineering Development Institute, Ilesa, Nigeria \\ ${ }^{5}$ National Agency for Science and Engineering Infrastructure, Abuja, Nigeria \\ Email: suppiedee@yahoo.com
}

Received June 11, 2012; revised July 23, 2012; accepted August 17, 2012

\begin{abstract}
This paper presents the corrosion characteristics and the accompanying changes in the microstructure of unalloyed ductile iron (DI) and austenitic stainless steel (ASS) in table salt medium representing an upper limit in an extreme marine environment. The individual corrosion rates of DI and ASS was evaluated for the maximum time period of $1200 \mathrm{hr}$. Using the immersion test technique, the corrosion rate of DI was evaluated and found to be four-orders of magnitude greater than that of ASS. The corrosion product morphologies of the DI showed that the nodular matrix was gradually covered up as immersion time progressed while the corrosion channels and volume of pits that initially formed in ASS respectively deepened and increased with increased exposure time. This work is important as a reference point for the quantification of the corrosion effectiveness of alloying DI. The microstructures of the corroded samples showed corrosion initiation and gradual accumulation of corrosion products.
\end{abstract}

Keywords: Atmospheric Corrosion; Ductile Iron; Austenitic Stainless Steel; Sodium Chloride and Microstructure

\section{Introduction}

The importance of austenitic stainless steel (ASS) in industrial applications and development cannot be overemphasized. Its excellent properties which range from high tensile strength, good impact, corrosion and wear resistances have found various applications in many industries. This material is used in almost all environments that require an optimization of these properties, some of which are low and high pressure boilers and vessels, fossil-fired power plant, flue gas desulphurization equipment, evaporator tubing, super heater reheating tubing and steam headers and pipes to mention but a few [1-3]. ASS is known for its corrosion resistance principally due to the presence of chromium which is soluble in the austenitic matrix. Chromium adds to the overall corrosion resistance through a passivation process by forming a complex spinel-type $\left\{(\mathrm{Fe}, \mathrm{Ni}) \mathrm{O}(\mathrm{Fe}, \mathrm{Cr})_{2} \mathrm{O}_{3}\right\}$ passive film [4-6]. This produces a coherent, adherent insulating and regenerating chromium oxide protective film on the

*Corresponding author. metal surface. The corrosion behavior of $18 / 8$ stainless steel and nickel-plated low carbon steel in cassava fluid has been investigated [7]. Very large amounts of carbon steels are generally used in marine applications, such as construction, nuclear and fossil fuel power plants, chemical processing, mining and transportation. Carbon steels are primarily affected by general corrosion and they are prone to deleterious corrosion by seawater $[8,9]$.

Ductile Iron (DI) consists of graphite in the form of nodules or spheroids in a matrixof either ferrite or pearlite [10,11]. DI is not a single material but part of a group of materials which can be produced to have a wide range of properties through control of the microstructure. The common defining characteristic of this group of materials is the morphological dominance of the graphite structure. In DIs, the graphite is in the form of spherical nodules rather than flakes (as in grey iron), thus inhibiting the creation of cracks and providing the enhanced ductility that gives the alloy its name. The formation of nodules is achieved by addition of nodularizing elements into the melt especially magnesium and less often, cerium [12]. Yttrium has also been studied as a possible nodularizer 
[12]. In contrast, the effect of chloride salts on the mechanical properties of gray cast iron has been recently reported [13]. The high temperature corrosion of two ductile cast irons (Si-Mo and Ni-Resist Alloys) in synthetic diesel and gasoline exhaust gases has also previously been reported [14]. Cast iron deterioration with time in various aqueous salt solutions has also been studied [15].

Seawater is a complex electrolytic solution, which has contributed to the corrosion of ocean oilrigs, water transport vessels (i.e. ships), tools, chemical plants, etc. It is a complex solution because it contains about 92 different chemical elements, the most common of which is $\mathrm{NaCl}$. The salinity of water is 35 part per thousand in which 35 parts of salt is found in 1000 parts of seawater [16].

Corrosion studies of metallic structures remain a major area of interest for scientific investigation. Recent effort in the study of mild steel and AISI 304L stainless steel in the presence of dissolved ions in seawater was recently reported [17] in which the Copper ions were found to have pronounced effect on corrosion rate.

In this work, we compare the corrosion rates of DI and ASS as a measure of the suitability or otherwise of ductile iron for marine environment applications with reference to ASS, an established corrosion resistant material. It is also to develop necessary experimental data to serve as a reference point for the corrosion of alloyed DIs, a major ongoing research program. The medium used in this work is a replica of extreme and "upper limit" "seaside" conditions. This is to allow us generate the highest possible corrosion response of the metallic structures under investigation in this type of high chloride profile environment.

\section{Materials and Method}

The plain DI used for this research work was produced with a uniform, well-graded and clean scrap following processing procedure already optimized at the Engineering Materials Development Institute, Akure, Nigeria with EMR-100 Rotary Furnace developed at the institute and already in commercial production. An effort in this direction has been used for smelting white cast-iron and low alloy cast-carbon steels [18]. The DI test specimens were fabricated by sand casting while the ASS is the classic 18/8 type referred to as "A2" in accordance to ISO 3506. The materials were spectrometrically analyzed with a XRF Spectrometer. With the spectrometer, analysis of up to 41 elements isobtainable within 2 minutes except for light elements such as $\mathrm{Al}, \mathrm{Mg}$ and $\mathrm{Si}$. The comparative composition by weight percent of the two materials under investigation is as given in Table 1.

The DI and ASS were cut into $20 \mathrm{~mm} \times 20 \mathrm{~mm} \times 10$ $\mathrm{mm}$ and $20 \mathrm{~mm} \times 20 \mathrm{~mm} \times 1 \mathrm{~mm}$ coupons respectively (Figures 1(a) and (b)). The coupons surfaces polished to 600 grit, thoroughly washed under tap, swabbed with acetone and then dried. Subsequently, the initial weight of the coupons was measured on a metler balance to $0.001 \mathrm{~g}$ accuracy. Each coupon was weighed and the dimensions carefully taken and recorded before exposure to the test media for a period of $1200 \mathrm{hr}$. Ten coupons each of both materials was fully immersed in table salt placed in separate containers. On the completion of each exposure test, the coupons were cleaned with wire brush, rinsed under tap and air dried prior to second weighing of samples to determine weight losses due to corrosion. This procedure is in consonance with ASTM G1-90 [19]. The corrosion rate of each coupon was calculated and the coupon examined under a software-driven optical microscope.

A small piece was cut from each coupon before the corrosion test to serve as a control specimen. It was mounted and mechanically ground progressively on grades of SiC impregnated emery paper (120 - 1200 grits) with water as the coolant. The ground coupon was then

Table 1. Comparative chemical composition of DI and ASS.

\begin{tabular}{|c|c|c|c|c|c|c|c|c|c|c|c|}
\hline \multirow{2}{*}{ Element } & \multicolumn{11}{|c|}{ \% composition of alloying elements } \\
\hline & $\mathrm{Fe}$ & $\mathrm{C}$ & $\mathrm{Cr}$ & $\mathrm{Ni}$ & Mo & $\mathrm{Si}$ & $\mathrm{Mn}$ & $\mathrm{P}$ & $\mathrm{S}$ & $\mathrm{Nb}$ & $\mathrm{Mg}$ \\
\hline DI (wt\%) & 82.242 & 3.600 & & & 0.014 & 2.000 & 0.300 & 0.007 & 0.010 & & 0.050 \\
\hline
\end{tabular}

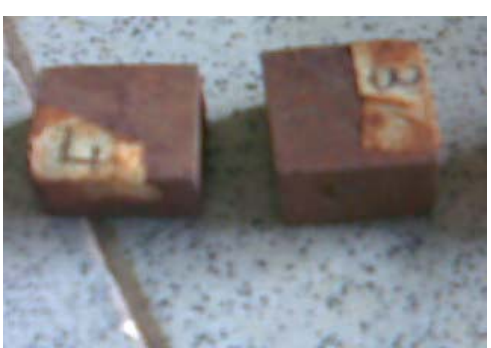

(a)

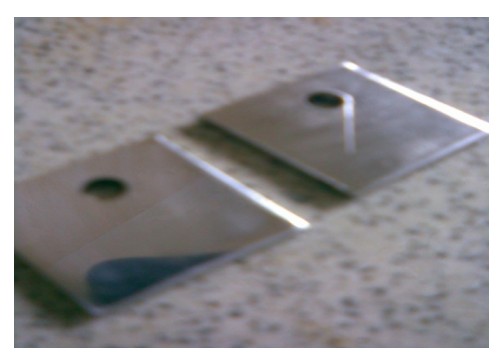

(b)

Figure 1. (a) DI coupons; (b) ASS coupons after the experiment. 
polished with 1.0 microns diamond polishing paste followed by 0.5 microns paste. The micrograph of each polished coupon showing the respective microstructural feature was also obtained.

\section{Results and Discussion}

The corrosion rate was computed in mils per year (mpy) with the standard expression [20-22].

$$
R=\frac{534 W}{\rho A T}
$$

where $W$ is weight loss in $\mathrm{mg}, \rho$ is the density of the coupons in $\mathrm{g} / \mathrm{cm}^{3}, A$ is the exposed area in square inch and $T$ is the exposure time in hours [20]. This shows that corrosion rate is linearly proportional to the weight loss.

Figure 2 shows the plots of weight loss of DI and ASS with time after immersion in table salt for $1200 \mathrm{hr}$. However, it can be observed that the weight loss in ductile iron increased progressively whereas the opposite effect is observed for ASS as it progressively decreased. This response can be attributed to increased anodic dissolution of the DI coupon in $\mathrm{NaCl}$. This is in contrast to the anodic passivation in ASS due to the presence of chromium in the austenitic matrix [4-6]. From the chemical composition of DI, (Table 1), molybdenum is in traces and chromium which could have enhanced corrosion resistance is conspicuously absent in the matrix of plain DI. When the ASS and DI coupons were physically

Weight Loss Data for DI and ASS

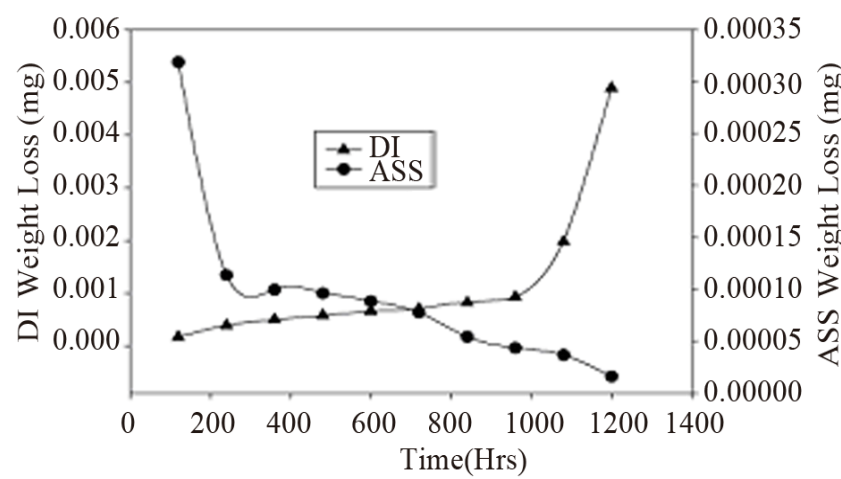

Figure 2. Weight loss of DI and ASS in NaCl.

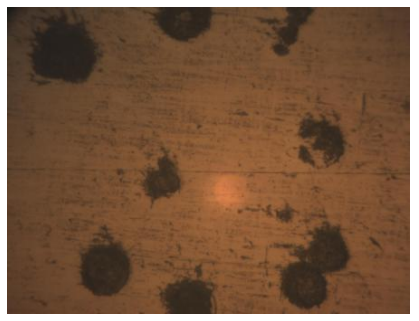

Before exposure

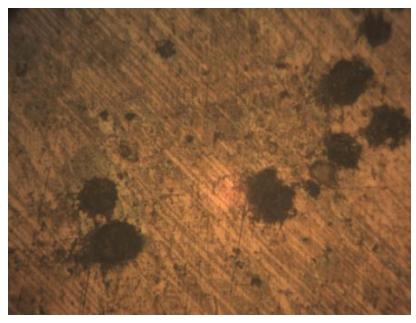

After $120 \mathrm{Hr}$

inspected, no significant change in appearance was observed in ASS coupons (Figure 1(b)). However, the DI coupons (Figure 1(a) were observed to be substantially corroded during the respective immersion time periods.

Figure 3 shows the comparative plots of the corrosion rates of DI and ASS in sodium chloride as time changes. A decrease in corrosion rate of for ASS with increasing immersion time was also observed following similar pattern when compared to the loss in weight. This effect could be attributed to the adherent thin passive film of chromium oxide formed on the metal surface [4-6]. This prevents the solution from contacting the metal itself.

The observations made in respect of the weight loss (Figure 2) is in agreement with that made for the corrosion rate (Figure 3) which is consistent with previously reported works [4-6]. It has previously been observed that that the presence of chromium alloying element adds to the overall resistance through a passivation process by forming a complex spinel-type $\left\{(\mathrm{Fe}, \mathrm{Ni}) \mathrm{O}(\mathrm{Fe}, \mathrm{Cr})_{2} \mathrm{O}_{3}\right\}$ passive film. This complex produces a coherent, adherent insulating and regenerating chromium oxide protective film on the metal surface; while molybdenum increases the ability of stainless steel to resist the localized corrosion in aggressive ion environments [7].

Figure 4 shows the microstructures of DI before and after immersion in $\mathrm{NaCl}$ at immersion times of $120 \mathrm{hr}$, $720 \mathrm{hr}$ and $1200 \mathrm{hr}$ depicting the corrosion product morphologies at the onset, middle and end of the experiment.

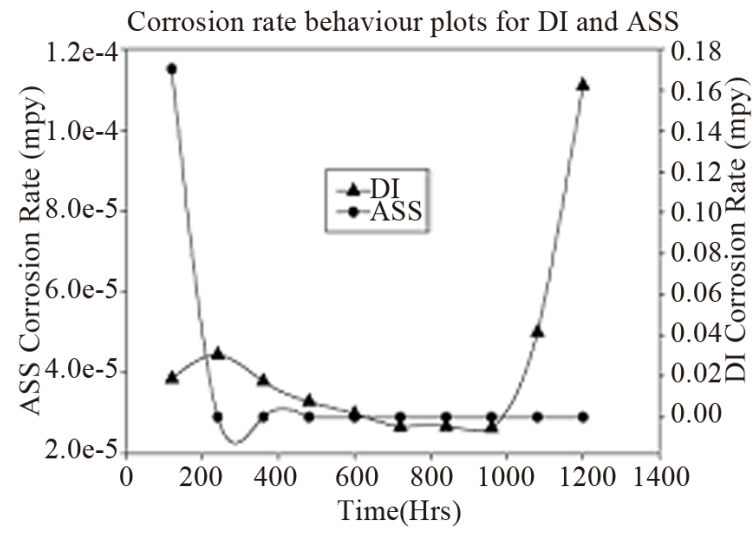

Figure 3. Corrosion rate of DI and ASS in NaCl.

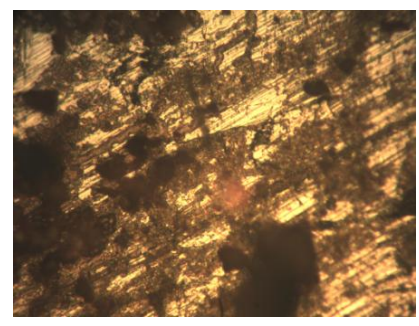

After $720 \mathrm{Hr}$

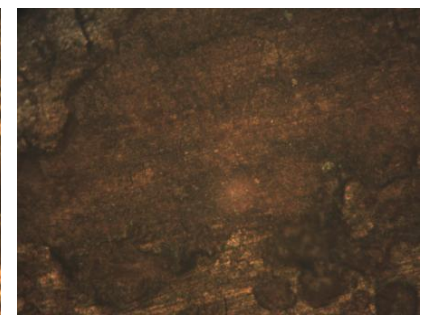

After $1200 \mathrm{Hr}$

Figure4. Microstructures of DI before and after immersion in sodium chloride $(400 \times)$. 


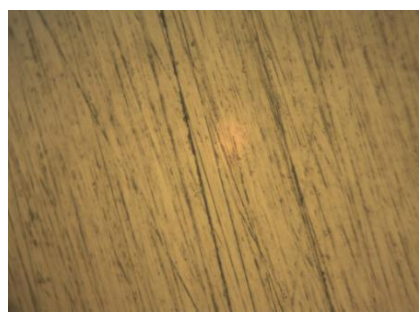

Before exposure

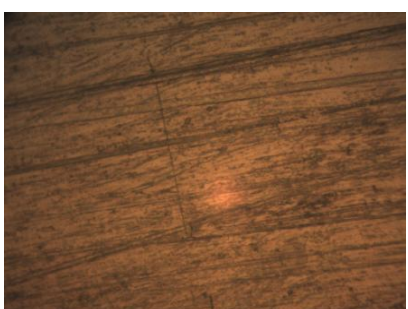

After 120 Hrs

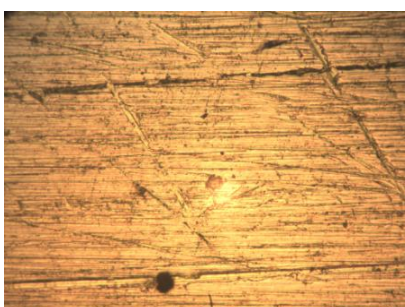

After 720 Hrs

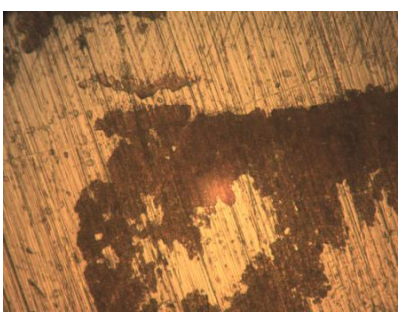

After $1200 \mathrm{Hrs}$

Figure 5. Microstructures of ASS before and after immersion in sodium chloride (400×).

The microstructures of DI (Figure 5) showed that the corrosion products gradually covered up the nodular matrix as the immersion time increased. Initially, the coupons revealed evenly distributed nodules in the pearlite/ferrite matrix of ductile iron.

Figure 5 shows the microstructures of ASS before and after immersion in $\mathrm{NaCl}$ at times $0 \mathrm{hr}, 120 \mathrm{hr}, 720 \mathrm{hr}$ and $1200 \mathrm{hr}$. It shows the morphologies of the surface corrosion product in which points of possible initial pitting corrosion are revealed. The volume of pits formed on each ASS coupon also increased progressively with time.

\section{Conclusion}

This paper has reported the study of corrosion behavior of DI and ASS in table salt representing an extreme marine environment as the media. After $1200 \mathrm{hr}$, the corrosion rate of DI was $1.1 \times 10^{-4}$ mpy compared to that of ASS which was $6.8 \times 10^{-7} \mathrm{mpy}$. The fact that ASS outperformed DI has been established but what this work has established is an almost 4 orders of magnitude difference in corrosion rate between the two materials. This is not unconnected with the presence of chromium in ASS coupons which greatly adds to the overall corrosion resistance through a passivation process by forming a complex spinel-type $\left\{(\mathrm{Fe}, \mathrm{Ni}) \mathrm{O}(\mathrm{Fe}, \mathrm{Cr})_{2} \mathrm{O}_{3}\right\}$ passive film. While corrosion rate of DI increased progressively with immersion time that of ASS decreased at comparable immersion time periods.

\section{Acknowledgements}

The authors appreciate the support provided by the management of Engineering Materials Development Institute, Akure, Nigeria where the entire bench work was carried out.

\section{REFERENCES}

[1] A. Galal, N. F. Atta and M. H. S. Al-Hassan, "Effect of Some Thiophene Derivatives on the Electrochemical Behaviour of AISI 316 Austenitic Stainless Steel in Acidic Solutions Containing Chloride Ions: I. Molecular Structure and Inhibition Efficiency Relationship," Materials Chemistry and Physics, Vol. 89, No. 1, 2005, pp. 38-48. doi:10.1016/j.matchemphys.2004.08.019
[2] A. I. Munoz, J. G. Anton, S. L. Nuevalos, J. L. Guinon and V. P. Herranz, "Corrosion Studies of Austenitic and Duplex Stainless Steels in Aqueous Lithium Bromide Solution at Different Temperatures," Corrosion Science, Vol. 46, No. 12, 2004, pp. 2955-2974. doi:10.1016/j.corsci.2004.05.025

[3] M. A. Streicher, "Stainless Steels: Past, Present and Future,” Climax Molybdenum Co., Ann Arbor, 1997.

[4] T. Nakayama and Y. Oshida, "Identification of the Initial Oxide Films on 18-8 Stainless Steel in High Temperature Water," Corrosion, Vol. 21, 1968, pp. 336-337.

[5] G. Okamoto and T. Shibata, "Passivity and Breakdown of Passivity of Stainless Steel,” In: R. P. Frankenthel and J. Kruger, Eds., Passivity of Metals, Electrochemical Society, New York, 1978.

[6] J. A. Platt, A. Guzman, A. Zuccari, D. W. Thornburg, B. F. Rhodes, Y. Ossida, D. W. Thornburg, B. F. Rhodes, Y. Ossida and B. K. Moore, "Corrosion Behavior of 2205 Duplex Stainless Steel,” American Journal of Orthodontics and Dentofacial Orthopetics, Vol. 112, 1997, pp. 6979.

[7] O. O. Oluwole, P. O. Atanda, O. A. Odekunbi and E. Odegbaju, "Corrosion Behavior of 18/8 Stainless Steel and Nickel-Plated Low Carbon Steel in Cassava Fluid,” Journal of Minerals and Materials Characterization and Engineering, Vol. 8, No. 10, 2009, pp. 803-811.

[8] M. M. Amin, W. B. Wan Nik and K. Yunus, "Oxidation Behaviour of Low Carbon Steel in Natural Water," Oriental Journal of Chemistry, Vol. 18, No. 2, 2002, pp. 183186.

[9] N. D. Prasanna, "Effect of Processes Variables on the Structure Mechanical Properties and Wear Characteristics of Austempered Ductile Iron,” Ph.D. Thesis, Bangalore University, Bangalore, 2000.

[10] R. Grundy, “The Development and Introduction of Spheroidal Graphite Irons into an Established Range of Malleable Irons to Meet Current Engineering Requirements," Transactions of Foundrymen, Vol. 72, 1979, pp. 141-151.

[11] K. L. Gillespie, “Troubleshooting Manufacturing Processes,” 4th Edition, SME, 1988, p. 4.

[12] C. S. Kanetkar, H. H. Cornell and D. M. Stefanescu, Transaction of American Foundrymen's Society, Vol. 92, 1984, pp. 417-428.

[13] O. Aponbiede and M. Okelekwe, "The Effect of Chloride Salts on the Mechanical Properties of Gray Cast Iron," Journal of Emerging Trends in Engineering and Applied 
Sciences, Vol. 2, No. 2, 2011, pp. 256-259.

[14] M. Misbahul Amin, "The CsCl- and $\mathrm{CsNO}_{3}$-Induced High Temperature Oxidation of Nimonic-90 Alloy at 1123 K,” Applied Surface Science, Vol. 115, No. 4, 1997, pp. 355-360. doi:10.1016/S0169-4332(97)00003-2

[15] R. Mehra and A. Soni, "Cast Iron Deterioration with Time in Various Aqueous Salt Solutions," Bulletin of Materials Science, Vol. 25, No. 1, 2002, pp. 53-58. doi:10.1007/BF02704595

[16] Department of Geology, San Jose State University, "Salinity and Variability," 2004.

http://geosun1.sjsu.edu/ dreed/105/exped6/5.html

[17] M. Mobin and H. Shabnam, "Corrosion Behaviour of Mild Steel and SS 304L in Presence of Dissolved Copper," Journal of Minerals and Materials Characterization and Engineering, Vol. 9, No. 12, 2010, pp. 1113-1130.

[18] J. R. Davila, A. Garrote, A. M. Gutierrez, P. Carnicer, L. Cobos and I. Erauskin, "New Applications of the Oxygas Rotary Furnace as a Means of Production in Melting,"
Proceedings of 1995 International Gas Research Conference, Cannes, 6 November 1995, pp. 2764-2773.

[19] ASTM G 1-90, "Standard Practice of Preparing, Cleaning and Evaluating Corrosion Test Specimens, Annual Book of ASTM Standards,” Vol. 3.02, ASTM, Philadelphia, 1993.

[20] A. Y. Badmos, H. A. Ajimotakan and E. O. Emmanuel, "Corrosion in Petroleum Pipelines," New York Science Journal, Vol. 2, No. 5, 2009, pp. 36-40.

[21] S. A. Umoren, U. M. Eduok and E. E. Oguzie, “Corrosion Inhibition of Mild Steel in $1 \mathrm{M} \mathrm{H}_{2} \mathrm{SO}_{4}$ by Polyvinyl Pyrrolidone and Synergistic Iodide Additives,” Portugaliae Electrochimica Acta, Vol. 26, 2008, pp. 533-546.

[22] N. D. Prasanna, M. K. Muralidhara, M. K. Agarwal and K. Radhakrishna, "Mechanical Properties and Corrosion Characteristics of IS400/12 Grade Ductile Iron,” Transactions of 57th International Foundrymen Congress, Osaka, 1 December 2009, pp. 89-95. 